\title{
LA TRAMA MADRE-HIJA EN LAS NOVELAS DE JULIA FRANCK Y VIOLETTE LEDUC
}

Soledad PEREYRA

Universidad Nacional de La Plata

María Julia ZAPARART

Universidad Nacional de La Plata

\section{I}

A comienzos de 2015, salió a la luz un artículo publicado en Signs: Journal of Women in Culture and Society de la Universidad de Chicago que bajo el sugestivo título de «Regretting Motherhood: A Sociopolitical Analysis» (2015) gestó una controversia más allá de los círculos académicos para los que estaba, principalmente, destinado el texto. Allí Orna Donath ponía en cuestión una vez más y a través de una larga investigación bibliográfica el retrato esencialista que la sociedad pinta sobre la maternidad, su asociación naturalizada como elemento inevitablemente constitutivo del significante «mujer» y también presentaba una evidencia contundente, con testimonios narrativos, de un grupo de más de veinte mujeres israelíes que se arrepentían de la maternidad. No de no tener hijos; no de no haberlos criado como hubiesen querido; no de no tener más hijos; no de haberse hecho un aborto, o bien de haber dado un niño en adopción. Se arrepentían de la maternidad. \#RegrettingMotherhood fue el tema imperante en la red social twitter durante semanas y cubrió numerosas páginas de periódicos europeos, espacios en los que se cruzaron opiniones por demás polarizadas, porque la mera pregunta o discusión ponía en crisis, como ha hecho muchas veces la literatura, la mismísima relación imaginaria, ya no tanto entre la madre como mujer, sino de la mujermadre con sus hijos.

Entre las feministas francesas de matriz psicoanalítica y postestructuralista que cobraron relevancia hacia los setenta algunas como Annie Leclerc, Monique Wittig, Hélène Cixous y Luce Irigaray han recobrado la maternidad como valor positivo de la diferencia sexual de las mujeres ${ }^{1}$. Donde Simone de Beauvoir en Le Deuxième Sexe (1949) se manifestaba en contra del presunto destino natural femenino unido a la maternidad, esta segunda ola de feminismo protagonizado por críticas francesas confirma aquellas ideas pero da una vuelta de tuerca que permite discutir la potencialidad

\footnotetext{
${ }^{1}$ Estas autoras y sus desarrollos críticos podrían inscribirse en el llamado feminismo de la diferencia, que se distingue de una corriente anterior, la del feminismo de la igualdad, precisamente por la constatación de la mujer como un sujeto-otro frente al hombre. A partir de esta hipótesis este feminismo capitalizará la diferencia femenina como valor por su alteridad en relación al hombre (cf, Rodríguez Magda, 1994).
} 
política de la maternidad como valor frente a un régimen de sentido falocéntrico que pone a la mujer en el lugar de objeto-pasivo. Irigaray enfatiza en algunos de sus textos los modos en los que la maternidad y el vínculo materno están entrelazados con la constitución de la subjetividad de la mujer, en tanto forma de determinación que tiene su origen primero en el lenguaje y el discurso que desde la hegemonía masculina y patriarcal se le impone a la mujer, dejando $s u$ discurso sobre el tema, en el espectro de lo inentendible, la incoherencia, esto es: la locura.

Ya en su tesis de doctorado, Spéculum de l'autre femme (1974), cuya hipótesis principal le valió ser expulsada de la École freudienne dirigida por Lacan, Irigaray establece la sospecha de que así como existe una relación con las estructuras del lenguaje de naturaleza pasiva, imitativa y mimética, del mismo modo las mujeres se vinculan, a través de un lenguaje que les resiste volverse sujetos activos de la expresión, con el discurso falogocéntrico ${ }^{2}$. Según Irigaray, aunque bajo la persecución de este razonamiento que tiene su origen en el lenguaje es necesario reconfigurar el orden simbólico individual, también es fundamental, dentro de este espectro, abordar y cuestionar la naturaleza problemática de las relaciones madre-hija individuales. Después de sus primeros libros, Irigaray publica dos textos más breves que tratan el tema de la relación madre/hija: Et l'une ne bouge pas sans l'autre (1979) y Le Corps-àcorps avec la mère (1981). Desde una reconstrucción de la visión de las relaciones entre madre-hijo bajo los modelos patriarcales imperantes en las sociedades occidentales que se originan en la mismísimo mito griego de La Orestíada que Irigaray lee, la autora determina que este vínculo se funda en la rivalidad y, con ello, en el matricidio (cf. Irigaray, 1980), en tanto la mujer dentro de la madre es negada a favor de la función maternal: «si la maternidad viene impuesta como un destino ineluctable que se desprende de aquel "pecado original", dará paso a una intolerable injusticia para las mujeres: la privación de sus derechos subjetivos» (Irigaray, 1992: 99). Para la feminista francesa la muerte de Clitemnestra es la mismísima representación de la exclusión de la madre-mujer de la cultura y de la configuración del orden simbólico. Irigaray lee en la historia literaria el registro de «imaginario primario», que remite a una potencialidad del vientre y cuerpo femenino, luego negada, por la criatura procreada, ese imaginario primario es el del encuentro cuerpo a cuerpo del infante con el cuerpo de la madre. De este modo, Irigaray retoma el significante de la mujer castrada

\footnotetext{
${ }^{2}$ Originalmente, el término falogocentrismo fue acuñado por Derrida para referirse a la unión entre el logos, como representante de la verdad y el sentido y el falo, como significante del logos paterno. El argumento que Derrida construye en «La farmacia de Platón» recompone que toda la idea de conocimiento, del campo político y de la cultura de Occidente tienen como referente el falogocentrismo, Este último término ha sido utilizado también por Luce Irigaray (1985) para describir la tradición occidental hegemónica que pone lo femenino en el lugar de la cosificación material u objetual, en contraposición a lo que define lo masculino, develando una posición estructuralmente asimétrica. De este modo, lo femenino vuelto objeto material queda sujetado a la economía de intercambios entre los sujetos-masculinos; son los hombres quienes, en tanto funcionan como referentes evidenciales de lo masculino al llevar el falo, están asociados a esa virilidad abstracta y a la cosmovisón dominante. En su texto Feminismo, diferencia sexual y subjetividad nómada (2004), Rosi Braidotti entiende el falogocentrismo como la matriz prototípica de Occidente que se refiere a los atributos importantes del sujeto y de la subjetividad en términos de la ponderación de lo masculino y la virilidad abstracta. Volviendo a Derrida, debemos resaltar que el feminismo no implica per se la inversión del falogocentrismo: «en el caso de que hubiera algo asî como el feminismo, habría muchas posibilidades o muchos riesgos de que este feminismo, precisamente en cuanto sistema que invierte o que propone invertir una jerarquía, reprodujese frecuentemente ciertos rasgos del falogocentrismo. Por lo tanto, no creo que se pueda decir simplemente que la deconstrucción del falogocentrismo implica un punto de vista feminista» (Derrida apud de Peretti, 1989).
} 
del psicoanálisis freudiano y la descompone en diálogo con los mitos clásicos que han convergido en una imagen de la mujer que, luego de la gestación, luego de que su vientre ha alimentado, resguardado y dado vida, es desplazada por un otro que en su hegemonía cultural y discursiva, transforma su otredad en la de ella. El resultado se evidencia en la literatura y en incontables discursos sociales sobre la mujer como madre, porque «[c]on algunos añadidos, nuestro imaginario continúa funcionando según el esquema de las mitologías y tragedias griegas» (Irigaray, 1985: 35). La mujer que siempre es madre aunque no haya tenido hijos, según Irigaray, se convierte en el otro asociado históricamente a la locura. La mujer-madre, propondrá Irigaray, no puede desdecir esta configuración que la tiene por «desagradable, amenazadora, horrorosa», que «como [un] Otro llega a amenazar lo que estaba destinada a sostener: la subjetividad masculina» (Zerilli, 1996: 176-177). Es así como la mujer-madre, y con ella toda mujer en su origen, es figura de la venganza, que con su fuerza productiva original no se somete a Zeus, tal como las Erinias persiguen a los culpables, en un decir que parece el de la locura y que por eso no son escuchadas del discurso normativo y patriarcal: «Mujeres en lucha, una suerte de histéricas, revolucionarias, que se sublevan contra el poder patriarcal que, en ese momento, se encuentra en vías de instaurarse» (Irigaray, 1985: 35).

Con reflexiones y deslindes filosóficos como los de Irigaray parece dialogar la escritura literaria de un vasto corpus de literatura consagrada escrita en lenguas europeas, en cuyo deslinde podrían encontrarse nombres disímiles como el de Virginia Woolf, Simone de Beauvoir, Elfriede Jelinek, entre otros. Todas estas voces, especialmente a lo largo del siglo XX, construyen interrogantes desde el discurso literario sobre la posibilidad de una identidad femenina donde los sufrimientos o alegrías de la maternidad no sean ya el criterio de conformación único de la identidad femenina; o bien de la identificación por un modo configurado desde la masculinidad. A pesar de sus diferencias estéticas, encuentran un punto de intersección en que son discursos literarios que configuran simbólicamente los significantes madre, maternidad y lazo maternal problemáticamente y desde su desautomatización.

Por su parte, el estudio de Marianne Hirsch (1989), especializado en la trama sobre el vínculo madre-hija, ha demostrado que en la mayoría de las narraciones en las que puede rastrearse durante los últimos dos siglos, esta trama tiende a negar la subjetividad de la madre a favor de la de la hija; en la búsqueda de agencialidad frente a una subjetividad negada, reprimida y dislocada, al tomar la pluma, las hijas vuelven objeto de sus narrativas a las madres, antes que sujetos en sí mismos. Contrario a las apariencias, este no es el caso de las tramas madre-hija (y en parte madre-hijo) que presentan algunas novelas de Violette Leduc, como L'Asphyxie (1946) y Ravages (1955), y las novelas de la alemana Julia Franck, especialmente Die Mittagsfrau (2007). En las obras de estas autoras, la trama madre-hija aparece para focalizar en el segundo segmento de esa supuesta unidad, en la hija, y así recorrer en la narrativa las extensiones y repercusiones del lazo maternal original en ellas y, finalmente, cómo esa madre objeto de la narrativa, es reemplazada del lazo por una hija que devela la ausencia de un vínculo natural. Los personajes de estas novelas y, con ellos, la operación de escritura que se balancea entre la autobiografía y la autoficción, le dan forma, vuelven materia de la literatura y con ello presencia, una forma de vínculo que, según Irigaray, con frecuencia se omite, se le quita evidencialidad, en lo no 
dicho: «No conozco mujer que no sufra en su relación con la madre. Y este dolor, que casi siempre se expresa con síntomas, proclama, traduce un silencio entre madre e hija y una incapacidad para identificarse» (Irigaray, 1985).

Ahora bien, la propuesta de Irigaray, en lugar de centrarse únicamente en los aspectos que reproducen una hegemonía del patriarcado a través de la maternidad como sí ocurre en numerosísimas páginas de Le deuxième sexe (1949) de de Beauvoir, se dirige, en cambio, a la potencialidad del vínculo entre mujeres, en la trama madre-hija, donde la reconstrucción es una fuente de placer, conocimiento y poder femeninos:

Una genealogía de mujeres dentro de nuestra familia: después de todo, tenemos una madre, una abuela, una bisabuela, hijas. Olvidamos demasiado esta genealogía de mujeres puesto que estamos exiliadas [...] en la familia del padre-marido; dicho de otro modo, nos vemos inducidas a renegar de ella. Intentamos situarnos dentro de esta genealogía femenina, para conquistar y conservar nuestra identidad. Y no olvidemos tampoco que ya tenemos una historia [...] que han existido algunas mujeres y que con demasiada frecuencia las olvidamos (Irigaray, 1985: 15).

II. «Ma mère ne m'a jamais donné la main» / «Mi madre jamás me dio la mano» es el comienzo de esta primera novela de Violette Leduc, y el trazado claro de la trama madre-hija, en tanto conflicto con la maternidad y los roles heteronormativos. Estos tópicos entrelazados fundan la narrativa de Leduc y se expanden por toda su obra, para volver a sentirse siempre en la escritura como un vínculo que se resiste a unir viejas y nuevas generaciones, tal como esa mano entre madre e hija que no se entrelaza.

La anécdota ya es hoy harto conocida no sólo por el reciente film de Martin Provost, Violette (2013), sino también porque, quienes se hayan iniciado en la obra de Violette Leduc lo saben: la autora dedica varias páginas de su monumental autobiografía, La Bâtarde (1964) a contar los orígenes de su carrera literaria. El retiro en Anceins, en la campiña francesa, con Maurice Sachs, en 1942, durante la ocupación, cambió para siempre el curso de la vida de Violette Leduc. Como ella le contaba las memorias de su infancia y primera juventud, día tras día, a un ya frustrado Maurice Sachs que intentaba darle forma a su autobiografía Le sabbat. Souvenirs d'une jeunesse orageuse, y también lo acosaba, pidiéndole que la amase, él terminó por obligarla a que pusiera por escrito sus recuerdos y sentimientos. De ese requerimiento de Sachs salió el primer borrador de L'Asphyxie (1946), que es un primer paso narrativo, el de las primeras reminiscencias infantiles, del largo y complejo proyecto autoficcional que constituye la obra de Violette Leduc.

Quien fuese la patrona del feminismo de la segunda ola, Simone de Beauvoir, también mentora y objeto de amor de Violette Leduc, describió en varias ocasiones la maternidad como momento pesadillesco de expropiación del cuerpo de la mujer devenida madre: «Con frecuencia no parece maravilloso sino más bien horrible que un cuerpo parásito prolifere dentro de su propio cuerpo; la mera idea de esta monstruosa hinchazón la atemoriza... es presa de imágenes de hinchazón, desgarramiento y hemorragia» (Beauvoir, 1974: 336).

Varios textos después de L'Asphyxie (1946), donde el tema encuentra su fundación dentro de su obra general, en la más exitosa de las novelas de Leduc, La Bâtarde (1964), la narradora interpela a su 
madre, pidiéndole que la devuelva al vientre que la gestó, que ella abra su vientre y la lleve de vuelta, otra vez al origen y a ese vínculo cuerpo a cuerpo, donde una vive dentro de la otra y por la otra (cf. Leduc, 1964: 33). Iluminando este pedido dentro de la trama madre-hija según la perspectiva de Irigaray, podemos verlo como una metáfora de «encontrar, reencontrar, inventar, descubrir, las palabras para nombrar la relación a la vez más arcaica y más actual con el cuerpo de la madre» (Irigaray, 1985: 41). La madre, Berthe, rechaza una y otra vez a esta hija según se nos narra en L'Asphyxie, ya que su origen bastardo le ha traído numerosas dificultades y, fundamentalmente, ha sido relegada a los márgenes sociales, ya que debe esconderse el hecho de que uno de los hombres de una casa de alto nivel social ha tenido una hija fuera del matrimonio con una de las criadas. Como madre, como todas las madres, diría Irigaray, Berthe Leduc queda fuera del orden simbólico legítimo y es para ella su hija, a pesar de la fascinación, adoración e incluso deseo que la pequeña siente por ella: «El orden social, nuestra cultura, el mismo psicoanálisis, así lo quieren: la madre debe permanecer prohibida. El padre prohíbe el cuerpo a cuerpo con la madre» (Irigaray 1985: 38). En L'Asphyxie, Berthe le cuenta a su hija: «El domingo, yo no salía. Me acostaba, leía. Dejé la ciudad. Se notaba. Busqué una habitación. En aquel tiempo, no había refugio para este tipo de faltas... Había ratas en el pasillo. Él ya no venía a verme. Él viajaba. Llegó dos meses después, entre dos trenes» (Leduc, 1946: 101; nuestra traducción).

De este modo, como muestran numerosos fragmentos de L'Asphyxie, es el padre/patriarcado el que deja a la madre, Berthe, como sujeto prohibido, bajo la sombra de la locura, y a una hija que se pierde en volver, como dicen en La Bâtarde, a esa matriz-vientre original, al lugar perdido, a un vínculo cuerpo a cuerpo como propone Irigaray, con la madre. L'Asphyxie se ocupa de ficcionalizar especialmente estos fragmentos de la historia de Violette Leduc. Berthe Leduc, la amargada y joven madre, instila en la pequeña un fuerte sentimiento de culpa por ser la fuente de su desgracia, la causa de su condena social. Berthe muestra ser, aunque sin amor y cariño, aparentemente, una madre por demás diligente, que mantiene una actitud excesivamente vigilante sobre la crianza de su hija en una sociedad pequeñoburguesa. Sin embargo, Violette siempre retorna a esa falta de ternura, como en el gesto de la mano, de una madre a quien temía y adoraba por igual. La fascinación de la hija e intento de volverse una en su locura, llega al punto de la obsesión amorosa. El yo ficcional de Leduc construye una trama madre-hija donde la segunda construye a la madre como parte de su imaginario amoroso, y la madre responde con más distancia, alejamientos y una nueva relación que su hija percibe como traición, tal como se expone Thérèse et Isabelle $(1955)^{3}$ a propósito de la partida al collège de la joven:

No tengo futuro en el colegio. Mi madre me lo dijo. Si te extraño demasiado te saco. El colegio no es un navío para las demás pensionarias. Ella me puede sacar de un instante al otro. Soy una pasajera. Me puede

\footnotetext{
${ }^{3}$ Thérèse et Isabelle fue, originalmente, la primera parte de la novela Ravages, pero no llegó a publicarse como parte de ésta, ya que en 1954, el editor, reticente, escandalizado y temeroso de polémicas, censuró el fragmento. Aunque Leduc incluyó un fragmento de Thérèse et Isabelle en la versión para publicar de La Bâtarde (1964) y la editorial Gallimard aceptó publicar una versión abreviada de Thérèse et Isabelle en 1966, el fragmento original completo no será publicado hasta el año 2000. La resistencia a la publicación surge, fundamentalmente, debido al modo explícito y lleno de erotismo con el que narraba las relaciones sexuales entre dos mujeres jóvenes.
} 
La trama madre-hija en las novelas de Julia Franck y Violette Leduc

sacar del colegio un día de inicio de clases, me puede sacar esta noche. [...] Es triste, pero no quiero irme de aquí. Mi madre se casó, mi madre me engañó (Leduc, 2000: 12-13; nuestra traducción). ${ }^{4}$

El (des)vínculo con la madre vacía de sentido al personaje autoficcional de las primeras novelas de Leduc y al yo autobiográfico de La Bâtarde. La escritura es el lugar de reencuentro con esa genealogía personal de mujeres que sugiere Irigaray ${ }^{5} \mathrm{y}$, también, con ese yo desubjetivado por los restos de un lazo siempre traumático.

Aunque la bibliografía crítica insiste sin matices en que para Violette Leduc el lazo primario y original con su madre siempre prevalecerá en tanto el primordial (cf. de Courtivron 1994: 290), como nos hace saber a lo largo de toda su obra, es necesario recomponer luego del rastreo del vínculo primario con la madre, cómo se reconfigura en las novelas el lazo madre-hija, donde el lugar de Berthe deja de ser, en los sucesivos textos, omnipresente. La madre como sombra de tormento debe desaparecer, más aún cuando el personaje crece junto a los sucesivos libros de la autora, y cada vez más siente que la madre no sólo la ha maltratado y abandonado a ella, sino también ha traicionado el vínculo de unión, de contagio entre una y otra que, como se exhibe en Ravages (1955) tenían:

- ¿Con quién anduviste?

- No anduve. Me invitaron. Cené en un restaurant, fui a lugares públicos.

-Antes de que te invitaran, te abordaron como se aborda... Prefiero no decirlo. Para esto me sacrifiqué.

- ¡No es cierto! ¡Si alguien se sacrificó, fui yo ! Si te digo que anduve por ahí todo el día, toda la tarde, toda la noche para olvidar, ¿me vas a creer?

— ¿Para olvidar qué? — dijo mi madre con una ordinariez afectada.

—Que el domingo y que los demás días estoy de más entre vos y él.

- ¡Celosa!

- No puedo pasarme la vida esperándote en mi habitación. Siempre tengo que estar ahí cuanto te vas y cuando volvés. Salí. ¡No cometí un crimen!

- Atormentaste a tu madre toda una noche, la hiciste morir a fuego lento (Leduc 1955: 72; nuestra traducción). ${ }^{6}$

El padre, André, ha abandonado a la madre, Berthe. Pero ésta decide abandonar al rastro que ese encuentro, con André, ha dejado, Violette, quien con su presencia la ha vuelto una mujer-madre, prohibida y hundida en la locura por siempre. El nuevo hombre, el padrastro del yo narrativo, será la forma de concretar el abandono de la madre por la hija.

\footnotetext{
${ }^{4}$ «Je n'ai pas d'avenir dans le collège. Ma mère me l'a dit. Si tu me manques trop je te reprendrai. Le collège n'est pas un navire pour les autres pensionnaires. Elle peut me reprendre d'un instant à l'autre. Je suis une passagère. Elle peut m'enlever du collège un jour de rentrée, elle peut me reprendre ce soir. [...] C'est triste mais je ne veux pas m'en aller d'ici. Ma mère s'est mariée, ma mère m'a trompée».

${ }^{5}$ Aquí debe recordarse que para Irigaray las genealogías son un medio para lograr relaciones entre los sexos más allá del falogocentrismo. Estas genealogías construyen narrativas entre mujeres con una morfología más allá del falo como elemento significativo.

${ }^{6}$ «-Avec qui as-tu traîné? / —Je n’ai pas traîné. On m’a invitée. J'ai dîné au restaurant, je suis allée dans des endroits publics. / -Avant qu'on t'invite, on t'a accostée comme on accoste... Je préfère ne pas le dire. C'est pour voir cela que je me suis sacrifiée. / —C'est faux! Si quelqu'un a été sacrifié, c'est moi! Si je te dis que j'ai traîné tout l'après-midi, toute la soirée, toute la nuit pour oublier, tu me croiras? / —Pour oublier quoi? dit ma mère avec une grossièreté affectée. / —Que le dimanche et que les autres jours je suis de trop entre toi et lui. / - Jalouse! / —Je ne peux pas passer ma vie à t'attendre dans ma chambre. Il faut que je sois toujours là quand tu pars et quand tu reviens. Je suis sortie. Je n'ai pas commis un crime! / - Tu as tourmenté ta mère toute une nuit, tu l'as fait mourir à petit feu».
} 
Un primer intento de subvertir y reconfigurar, de virar, de la trama madre-hija como es planteada en el inicio, se encuentra ya en L'Asphyxie, por un lado, con la reafirmación de otro vínculo maternal, con la abuela y, por el otro, con un intento de desplazamiento del lugar del padre a través del trabajo simbólico con los objetos a través de dos anécdotas puntuales que ocupan un lugar central en la novela.

En primer lugar, ante los sucesivos ataques de rabia inttercalados por el desprecio y la indiferencia de la madre que configuran un tono narrativo brutal -aquel que con frecuencia es rechazado por muchos lectores de la autora-, podemos rastrear ya en L'Asphyxie que el yo narrativo encuentra finalmente cobijo y redención a su eterna culpa, en su abuela, Fidéline, único personaje con quien entabla un vínculo entre madre-hija entendido de modo tradicional, como protectora de su progenie. Es a ella a quien se acerca físicamente con los juegos y gestos de una hija con su madre: «Me refugié en los brazos de mi abuela. Besé su cabello, sus ojos, el hueco de sus mejillas. Saqué y volví a poner las gruesas horquillas que sostenían su rodete. Habitualmente, le demostraba así mis sentimientos por ella» (Leduc, 1946: 36; nuestra traducción).

En segundo lugar, en esta reconfiguración de la trama madre-hija, la hija es verdadera protagonista y actante de dos episodios fundamentales. En esta novela se narran dos pérdidas materiales que pueden leerse como la metáfora de la pérdida del padre y, con ello, de la madre que acepta y restituye ese orden simbólico patriarcal. El yo narrativo niña pierde en una instancia una medalla de oro, único regalo de su padre, que tenía aparentemente grabado el escudo de la familia y, en otra ocasión, un paraguas. La pérdida de la medalla de oro no es sólo una pérdida económica importante para la empobrecida familia de la niña, sino también la pérdida del rastro del padre. La anécdota extiende aún más sus fronteras simbólicas si tenemos en cuenta que la niña se da cuenta de la pérdida de la medalla cuando llega a la casa, después de haber ido a la casa del padre para intentar conocerlo y fracasar en esta empresa. La frustración que expresa Berthe a su hija tras este fracasado episodio es cruda y carente de cualquier forma de compasión. Hacia el final del volumen, una nueva pérdida termina de borrar el camino hacia el padre y el orden patriarcal frente al cual la niña sólo quiere escapar. En esta ocasión el yo narrativo pierde un paraguas nuevo, símbolo fálico asociado al padre (André) que no la ha reconocido pero que tiene la obediencia y respeto de la madre. El descubrimiento de este olvido/descuido desata una violenta golpiza de la madre a su hija ${ }^{7}$. Con la pérdida de la medalla $\mathrm{y}$, hacia el final, la pérdida del paraguas, el yo-narrativo ha concretado el borramiento del lugar del padre y reafirmado los rastros de la trama-vínculo entre la madre-hija. Podemos entonces entender el episodio, siguiendo a Irigaray, como pequeño acto de sublevación contra un orden patriarcal que se desentiende del sujeto femenino y como búsqueda de recuperación de un espacio de lazo efectivo entre madre e hija. Irigaray diría, entonces, que el gesto de perder el objeto del padre no es duelo rival,

\footnotetext{
${ }^{7}$ La madre es la encarnación misma del estereotipo de la mujer ambiguo frente a un modelo social heteronormativo, patriarcal y machista, pero que simultáneamente no puede superar su existencia en un tiempo donde el feminismo de segunda ola todavía no ha ocurrido. Aunque, por ejemplo, en La Bâtarde le dice a su hija «Tous les hommes étaient des salauds» (Leduc, 1964:53), también se vanagloria de su amante y golpea y maltrata a su hija, como discutimos arriba, en el nombre del orden del padre (cf. Locey, 2002: 28).
} 
competitivo, «sino deseo de abolir al que ha roto artificialmente el vínculo con la madre para hacerse con el poder» (Irigaray, 1985: 40).

Con posterioridad, en el orden cronológico y en su coincidente configuración literaria en las siguientes obras de Leduc, la reconfiguración de la trama madre-hija se presentará cambiando el primer término: es Simone de Beauvoir, su madre literaria e intelectual, quien pasa a ocupar el lugar de la madre biológica y quien, como aquella, no sólo será admirada y querida, sino que se volverá la obsesión y mismísimo objeto de deseo y seducción del yo narrativo de las obras posteriores. Si de partos simbólicos del mundo intelectual se trata, el rastreo de las fechas nos sirve para apoyar esta lectura: el comienzo de la carrera de Leduc como una verdadera escritora coincide con otra creación literaria de Beuavoir, la prestigiosa revista Les Temps Modernes. Esta publicación surge en 1945, fundada por la dupla Sartre-de Beauvoir y, allí, en el segundo número, Violette Leduc publica «Une mère, un parapluie, des gants» (Noviembre, 1945) ${ }^{8}$. El vínculo erótico y amoroso del yo autoficcional de Leduc con Beauvoir es sólo la forma iterada del vínculo original con la madre, tal como lo ha vivenciado. Beauvoir desplaza en la escritura y en la vida a la madre original y se convierte en la madre simbólica en las tramas madre-hija de Leduc, para quedarse hasta en sus últimas obras, no únicamente como una reproductora en el sentido biológico, sino, y rompiendo con el binomio heteronormativo y patriarcal, como productora de una escritora y figura literaria única:

Simone de Beauvoir ha luchado por el principio de Estragos. Ha luchado con todas sus fuerzas. Está sublevada. Ha llevado mi texto a otros editores. No lo quieren. El libro aparecerá, pues, privado de su comienzo. Es cuestión de aceptar o retirarse.

-Mi pobre Violette... Sea valiente - me dice.

Escucho sus consuelos desde lo hondo de mi fosa. Me compadece pero no me hiere. No reacciono. [...] Simone de Beauvoir es mi amiga, ha tomado mi defensa ante mis verdugos. Yo les ofrezco mi piel. El libro será confiscado, el editor no gana un cobre con lo que yo escribo... Simone de Beauvoir está indignada. Yo estoy trastornada. Mi texto disgusta. El erotismo, en esta época, asusta. Debemos aceptar. Ella lucha todavía, sentada en su pequeño diván. [...]

—Las cosas andan mal, andan mal, en verdad - murmura.

Es casi maternal (Leduc, 1976: 22).

III. Cuando en 2007 la novela Die Mittagsfrau / La mujer del mediodía fue premiada con el premio literario alemán más prestigioso, el Deutsche Buchpreis ${ }^{9}$, en la serie de entrevistas que le sucedieron la autora, Julia Franck, se ocupó de confirmar el sospechado ímpetu autobiográfico que había gestado la escritura de su texto: «Cuando tuve mi primer hijo hace siete años, me invadió la necesidad de responder a la pregunta de qué puede llevar a una mujer a abandonar a su hijo y a estar convencida de que en cualquier otra parte él estará mejor que con ella» (Geu/Franck, 2010). La experiencia de la

\footnotetext{
${ }^{8}$ Posteriormente, Leduc publicará otros fragmentos de su obra, antes de alcanzar la publicación en libro. Por ejemplo, en el número 25 de octubre de 1947 publicará «L’Affamée», y en el 26 del mes de noviembre de 1947 «L'Affamée, suite et fin», entre tantos otros. Para un desarrollo extensivo de las publicaciones en revistas de Leduc, tanto para Les Temps Modernes como para la revista femenina Pour Elle, véase la bibliografía y estudio de Carlo Jansiti.

${ }^{9}$ El Deutscher Buchpreis es el galardón que otorga la Asociación de Escritores y Libreros Alemanes a, entre otros, la mejor novela en lengua alemana del año. Es un premio de reciente creación y que no sólo ha adquirido rápido prestigio, sino que también concede una generosa dotación económica como recompensa. El jurado va cambiando cada año y su fallo se anuncia al inicio de la Feria del Libro de Frankfurt.
} 
propia maternidad impulsa a la autora hacia la escritura que lleva en sí misma el movimiento de la reconstrucción de su propia genealogía de mujeres.

Die Mittagsfrau es la cuarta novela de Julia Franck y en ella se abre la ficción con el abandono de una madre (Helene) a su hijo (Peter) en el andén de una estación de tren. En el caso de Franck, esta no será una mera anécdota o golpe duro con el cual, efectivamente, mantendrá al lector en plena expectación hasta el final, sino el motivo crítico que se deconstruye y reconstruye a lo largo de la novela: la crisis de la visión esencialista sobre el rol materno y el lazo entre la mujer y la emocionalidad maternal, que se suponen como biológicamente innatos.

Estructuralmente, la novela puede pensarse como un extenso flash-back que transita entre un prólogo y un epílogo amargo, en el cual no puede filtrarse el más mínimo margen de una promesa de reunión entre madre e hijo, donde el lenguaje literario, como ha señalado la crítica, es simple, llano, duro y no habilita espacio para un atisbo del sentimentalismo, que ya es inherente a las situaciones que narra. Hay un cambio en la novela en relación con la perspectiva narrativa del prólogo y epílogo con respecto al centro, resto, fecundo en narración y reconstrucción de los pormenores de una historia individual. Las partes que dan marco a la obra, el prólogo y el epílogo, están escritos desde la perspectiva del hijo (Peter); el centro, lo que contiene esa inauguración y ese cierre del ciclo narrativo, están escritos desde la perspectiva de la madre-hija, Helene. Este esquema, que puede parecer simplemente un desplazamiento de la voz de mujer-hija-madre por la del hijo-hombre, es, por el contrario, la focalización en su narración. De este modo, esta estructura narrativa encuentra su punto de intersección con la estructura familiar-personal de quien escribe: tanto en Leduc como en Franck, la ficción de contenido autobiográfico sobre la trama madre-hija es un movimiento de acercamiento a las subjetividades que social y familiarmente fueron abandonadas y silenciadas, consideradas figuras marginales y del linde. La escritura les concede un lugar de afirmación de una subjetividad negada por haber negado su lugar de madres y por haber puesto en crisis el lugar de sus propias madres.

El texto de Julia Franck pertenece a un notable número de novelas de la literatura alemana actual, que refleja la vida familiar durante la época del Nacionalsocialismo. Julia Franck, autora de la tercera generación tras la Segunda Guerra Mundial, construye en esta obra, recuerdos individuales y colectivos del Tercer Reich ${ }^{10}$. Más allá de haber sido críticamente etiquetada como literatura de postmemoria ${ }^{11}$

\footnotetext{
${ }^{10}$ Franck cuenta: «La escritura de la novela coincidió con el nacimiento de mi segunda hija. Para mí fue muy importante clausurar este relato que se venía arrastrando entre dos generaciones, no sólo desde el lado de mi padre, que había sido abandonado por su madre, sino desde el lado de mi madre, en el que hubo una historia similar. La ficción era una manera de romper con esta cadena de abandonos; gracias a la literatura pude cerrar este agujero negro en mi vida. Yo no conocí a mi abuela paterna y prácticamente tampoco a mi padre, que murió a los 39 años, de un tumor cerebral, y que fue incapaz de vivir con una mujer. La literatura me permitió ponerle un punto final a esta trama de abandonos» (Friera/Franck, 2009: s. p.).

${ }^{11}$ La narración, relato o literatura de postmemoria se ha vuelto un término ya casi desgastado por su enorme uso y proliferación a través de diversas formas, en los textos de críticos y académicos de diversas disciplinas, tales como Marianne Hirsch, Saul Friedlander, Aleida Assmann y Jürgen Straub. En todos los casos, como es sabido, el foco de investigación está en la discusión sobre la memoria en un nivel transgeneracional. De este modo, esta línea crítica indaga no sólo en los efectos históricos, sino en el impacto y estrategias de aproximación a las experiencias históricas traumáticas, fundamentalmente del Holocausto y del Nacionalsocialismo, en los hijos y nietos de la Segunda Guerra Mundial, quienes no han vivenciado, vivido, de primera mano, estos hechos, pero quienes han elaborado una experiencia nemónica sobre
} 
o incluso reducida a un nuevo episodio de la mucho más comercial categoría de «literarischen Fräuleinwunder» (Hage, 1999) ${ }^{12}$, de la cual Franck fue víctima al publicar su segunda novela, Liebediener (1999), la novela de Die Mittagsfrau se inscribe claramente en un diálogo con la crítica feminista, en tanto que desde la experiencia ficcional construye una narración donde los personajes femeninos ponen en crisis la imagen tradicional y heteronormativa de la mujer. Si especulamos cruces entre la ficción y la figura de autor de Julia Franck, fundamentalmente a partir de aquel bochornoso episodio y escándalo de fin de siglo del Fräuleinwunder, encontramos una nueva evidencia que nos permite respaldar la lectura feminista de Die Mittagsfrau. Poco después de la polémica por el artículo de Hage en Der Spiegel, en el 2000, el reconocido diario Die Welt le pidió a diversas escritoras involucradas que compusieran ensayos sobre el asunto, dando su perspectiva crítica. En ese momento, Julia Franck entregó el ensayo «Das Wunder Frau», donde critica de lleno la categoría de Fräuleinwunder, aunque remarca como único aporte del texto de Hage que es cierto que las mujeres escriben de forma distinta que los hombres, principalmente por el impacto que la valoración imprecisa y desigual ha producido en sus obras:

An den Büchern meiner Kolleginnen ist mir aufgefallen, daß sie eine nüchterne Erzählweise bevorzugen. Wo männliche Kollegen ungehemmt. Mut zum Pathos beweisen, beschreiten weibliche Autoren, denen der Kitschverdacht aufgrund ihres Geschlechts viel schneller anhaftet, einen Grat zwischen Beiläufigkeit und Nüchternheit. Die Andst vor dem Süßen und Netten, die vor dem Anrührenden und Gefühlvollem ist groß (Franck, 2008: 234).

Franck propone así marcar la diferencia literaria femenina como «weibliche Nüchternheit» y con ello se alinea con el pensamiento feminista de segunda generación pero desde la crítica literaria, porque piensa la capitalización y valoración de la diferencia femenina, antes que su detrimento o bien, antes que buscar su equivalencia con la contraparte masculina. Paradójicamente, el diario Die Welt rechazó el ensayo de Franck por considerarlo demasiado feminista para ser publicado ${ }^{13}$, aunque a partir de ese momento Julia Franck se inscribe como voz de un nuevo feminismo en el siglo XXI, que encuentra su espacio de intervención fundamentalmente en los textos ficcionales, como por ejemplo en Die Mittagsfrau ${ }^{14}$.

ellos. En el caso de Julia Franck, tanto Die Mittagsfrau, como las novelas Lagerfeuer (2003) y Rücken an Rücken (2011) pueden pensarse como narraciones de la postmemoria.

${ }^{12}$ Fräuleinwunderliteratur fue un término moldeado por el crítico Volker Hage en 1999 para un artículo publicado en la revista Der Spiegel. En este artículo Hage agrupaba jóvenes autoras y encontraba un punto de encuentro en que «über Erotik und Liebe, $[\ldots]$ schreiben die jungen Autorinnen allesamt nüchtern und ohne Illusionen». La crítica especializada rechazó unánimemente el término, por considerar que se fundaba en simplificaciones y clichés; sin embargo los medios y el mercado editorial lo tomaron como una etiqueta para promocionar los libros escritos por mujeres a fines de los años noventa. Esto generaba una gran paradoja: la inclusión dentro del Fräuleinwunder le garantizaba a las escritoras mayor circulación mediática y más ventas, pero significaba la postergación u olvido de una valoración crítica más seria de su trabajo (cf. Merley, 2008: 201).

${ }^{13}$ El texto apareció por primera vez completo en la publicación especializada Women in German Yearbook (2008).

${ }^{14}$ Mucho se ha escrito sobre la relación de la obra de Franck con el feminismo, especialmente pensándola como una heredera de la corriente feminista alemana de los años setenta. En uno de estos estudios, Biendarra establece que Franck no es exactamente heredera de la literatura feminista de los setenta porque trabaja con personajes femeninos que, a diferencia de aquella, no están idealizados, sino que son imperfectos, con frecuencia realizan acciones reprochables y muchas veces producen la indignación de críticos y lectores por la ausencia de juicio moral en ellos (cf. Biendarra, 2004: 217-218). 
En la novela de 2007, Franck escribe un relato de imbricación personal y, conjuntamente, que tiende puentes con la memoria cultural alemana. Al igual que la abuela paterna de la autora, que abandonó a su propio padre, la enfermera y protagonista de la novela, Helene escapa de la ciudad de Stettin hacia Berlín. Apenas terminada la Segunda Guerra Mundial, este personaje femenino abandona a su hijo Peter de siete años en el andén de una estación de tren. Como fue apuntado arriba, la perspectiva aquí es de Peter, es necesario ir por el derrotero narrativo del centro del texto, y como tal en estas primeras páginas se destacan las sensaciones del niño. Desde la mañana, Peter sigue con esmero los confusos movimientos de su madre por el humilde departamento y comienza por buscar un justificativo a esa primera actitud esquiva de la madre: «Peter quería decirle que lo sentía mucho, que se había olvidado la cerradura, que no había podido ayudarla, pero sólo fue capaz de articular una palabra, y ésa fue mamá. Quiso cogerle la mano, pero ella se soltó y salió delante de él» (Franck, 2009: 24-25). En este fragmento, vemos cómo el hijo, al igual que el yo-narrativo de Leduc, busca y no encuentra la mano de su madre. El cuerpo a cuerpo con la madre de Irigaray, se indica aquí, nuevamente, como en Leduc, en la metáfora de la mano que se tiende a la madre como pedido de reparación de la protección original en el vientre, que ella rechaza, una y otra vez: «Peter se puso a dar palmadas y empezó a silbar hasta que su madre se detuvo súbitamente ante él y le ordenó que se callara. Peter intentó cogerle de nuevo la mano, pero la madre le preguntó si no veía que llevaba la maleta y el bolso» (Franck, 2009: 25).

Ya en la primera estación de tren, cuando tienen que subirse al vagón en movimiento, Peter insiste en tomarle la mano, pero éste será el momento definitivo que confirma la separación del hijo:

[...] la madre de Peter logró avanzar el metro decisivo, apretó a Peter, lo empujó, lo metió con todas sus fuerzas en el tren. Peter se dio vuelta, sujetó la mano de su madre, la agarró fuertemente, el tren traqueteó, se puso en movimiento, las ruedas giraron; la madre echó a correr, Peter se aferró a la puerta, sujetó a su madre, iba a demostrarle lo fuerte que era. ¡Salta!, le gritó. En ese instante sus manos se soltaron (Franck, 2009: 28).

El abandono que cierra el prólogo, que rompe el vínculo con el hijo, reedifica la subjetividad femenina de Helene como individuo que no encaja en los patrones tradicionales asociados con la mujer y es, asimismo, la realización de la narrativa personal que le da voz, que en la narración la desobjetiviza del escrutinio polarizado y moralista y expone su intento de individuación: «Ésa no era Helene. Helene no era mami de nadie, no tenía que darse la vuelta» (Franck, 2009: 415). Ese abandono, como en Leduc, es el proceso constitutivo, el origen mismo de la escritura y el destino al que conduce su derrotero.

De la estación de tren donde Peter se queda esperando en vano el regreso de su madre se asiste a un flash-back que reconstruye la infancia de Helene y su hermana mayor, Martha, en el seno de una familia burguesa venida a menos en un pueblo de provincia. Hijas de un imprentero de prestigio en la comunidad y de una judía extravagante que colecciona plumeros y cuanto objeto encuentra por las calles, sin reparar en la existencia de esas niñas, las hermanas perderán al padre, que muere al poco de regresar, sin una pierna, de la Primera Guerra Mundial. Con la madre sumida en una locura que no tiene retorno y el negocio de la imprenta en bancarrota, deciden irse a vivir con una tía rica a Berlín. 
Son los años locos, felices, del jazz, la cocaína y las fiestas hasta altas horas de la madrugada. Esa felicidad a cuentagotas dura poco. Martha se hunde en sus adicciones; Helene se enamora de un estudiante de letras, pero terminará en manos de Wilhelm, un hombre despótico, nazi, quien modifica los papeles y partidas de nacimiento de Helene para que no salte la chispa del «origen impuro» de su mujer. A pesar de un primer aborto con el que rechaza su rol de madre, Helene decide tener al hijo producto de su relación con Wilhelm. El momento del parto expone en un gesto, la contradicción que encierra el dar a luz al hijo, que significa encuentro pero también, como apunta Irigaray, primer abandono, desplazamiento, del lugar de la madre. En la sala de partos, ansiosa y agotada, Helene vacila confundida sobre el ser vivo que puja por salir de su cuerpo y expresa las contradictorias sensaciones como un proceso de diferenciación entre madre e hijo:

¿La cabeza? ¿La cabeza está fuera? Helene no podía creerlo. Notó algo gordo entre las piernas, algo que no le pertenecía, ya no, lo notó por primera vez, ya no sólo dentro de ella, el cuerpo de su bebé, sino también junto a ella. El médico no le prestó ninguna atención. Helene fue palpando con la mano hacia abajo. Quería coger la cabecita. ¿Aquello eran pelos? ¿Los pelos del bebé? fuerte.

¡Fuera esas manos! A Helene le apartaron el brazo, la sujetaron por la muñeca y la agarraron muy

Recordemos que la noción del psicoanálisis del «cuerpo a cuerpo» que Irigaray recupera, tiene que ver con la interrupción de la relación física, corporal entre madre-hijo, debido a la imposición del lenguaje y de la ley del padre que busca interrumpir ese contacto uno a uno, entre madre e hijo (cf. Forcinito, 2004: 80). Ahora bien, esta reflexión de Irigaray parece pertinente para este momento de alumbramiento. La madre, Helene, quien extrañada quiere palpar aquello que se ha apartado de la unidad de su cuerpo, es reprimida por la palabra del hombre (el médico que grita «¡Fuera esas manos!») y el sistema que él comanda, el de las enfermeras y la institucionalización médica, la someten por la fuerza y prohíben la relación corporal con la madre, el contacto «cuerpo a cuerpo» con la cría que acaba de dar a luz.

El acto mismo de llevar a cabo el abandono del rol materno décadas antes por parte de su propia madre, Selma, quien había rechazado a sus hijas y las había dejado sin ningún tipo de cuidado por la desesperación que sentía por un hombre que había perdido para siempre, es realmente el prólogo del sujeto-madre, Helene. Nuestra protagonista, al enterarse de que el hijo que recién ha nacido de su vientre es un hombre y no una mujer, como esperaba, se siente especialmente conflictuada, ya que su hijo varón imposibilita la recomposición de un lazo madre-hija que ella nunca tuvo. Helene se debate con fuerza, intentando encajar en el rol de madre, tal como socialmente se espera de ella, pero pronto se encuentra con que el niño debe irse. Ella se resiste a asumir que su «deseo quede anulado por la ley del padre» (Irigaray, 1985: 41). Por eso debe deshacerse de su hijo, para restituirse en su corporalidad, y este relato de abandono en la búsqueda de su recuperación es el que se encuentra en las páginas del prólogo de la novela.

El prólogo permite desovillar la narración que no tendrá por asunto principal la trama de madre/hijo, sino en todo caso, al igual que en Leduc, el intentar deconstruir y reconstruir la trama madre/hija o, incluso, la trama-madre. El personaje de Helene Würsich y este recorrido que arranca 
textualmente después de la Segunda Guerra Mundial, con la ocupación rusa de Berlín y el abandono de Peter, permite al lector ir hacia atrás para reconstruir, como diría Irigaray, esa genealogía olvidada con la madre, Selma Würsich. Más allá de la historia de Peter que da marco al texto, el vínculo de nuestro personaje, Helene, con su madre, Selma, es el que gesta toda la narración posterior y el que encuentra paralelismos sorprendentes con la relación entre el yo autoficcional de Leduc y la madre (Berthe). Del mismo modo que Leduc encuentra una reconstrucción del vínculo materno en otras mujeres, en La mujer del mediodía también encontramos esta forma de la trama madre-hija. En primer lugar, la criada de origen eslavo, Mariechen es quien busca compensar la indiferencia de Selma, tratando a la pequeña Helene como su propia hija; también es Mariechen quien le da el nombre al bebé y quien intenta amamantarla cuando la madre no lo hace. Del mismo modo, ya adolescente, será Martha, la hermana mayor, quien ocupará el espacio vacío del lazo madre-hija. Aquí, como en la dupla Simone-Violette, la fascinación de las hijas por la madre, se restaura en un vínculo que además del rol maternal, incluye el deseo y lo erótico.

$\mathrm{Al}$ igual que personajes de las novelas de la francesa Leduc, la pequeña Helene de Franck admira y busca con fascinación a la madre, Selma, quien es igualmente despiadada y violenta con su hija, como el personaje francés de madre que hemos desarrollado en la sección anterior:

Sin embargo, mientras la madre abroncaba a sus hijas y maldecía por no haber parido más que engendros inútiles, Helene repetía una y otra vez la misma frase, como si fuera una letanía: ¿Puedo peinarte? Su voz temblaba: ¿Puedo peinarte? Cuando una tijera voló por los aires, Helene levantó los brazos y se tapó la cabeza para protegerse. ¿Puedo peinarte? Y se acuclilló bajo la mesa. ¿Puedo peinarte? (Franck, 2009: 37).

Helene-niña admira la belleza exótica de su madre y busca, nuevamente, el contacto físico con su admirada madre, pidiéndole que le permita peinarla. Nada detiene el insistente pedido, como décadas después la mano de Peter busca reiteradamente la mano de la madre-Helene, el pedido no se detiene ni ante las tijeras que su madre le arroja por lo alto. Pero Selma, como Berthe Leduc, no puede sentir amor y ternura maternal por su hija; es una mujer enceguecida por la locura que todavía vive aferrada a la imagen de su marido que se fue a la guerra y sus cinco hijos muertos. Las tijeras que la madre arroja, objeto-herramienta para el corte voluntario, son proyección de las manos de Helenemadre y su hijo Peter que, en una estación de tren, mucho tiempo después, no se juntan, y se usa el abandono como herramienta para asegurarse que estén, por fin, separadas.

IV. Aunque escritas en diferentes tiempos y con diversos própositos y públicos, las novelas con contenido autobiográfico de Violette Leduc y de Julia Franck, pueden exhibir aspectos fundamentales sobre la herida que la literatura exhibe en relación a los discursos históricos, literarios y sociales sobre la mujer, la maternidad y la realidad material de las mujeres en general. Tal como ha sido expuesto a lo largo del artículo, en varias oportunidades, tanto Leduc como Franck han alzado su voz para realizar una crítica feminista, pero en los dos casos esta crítica se ha concretado con mayor impacto como forma de resistencia al modelo heteronormativo en la construcción de narraciones literarias. Al igual 
que propone Irigaray para el caso de Antígona, la narrativa de abandono a partir de la trama madrehija en Leduc y de Franck se construye a partir de personajes (e historias personales) de mujeres cuya forma de rebelión expone la dislocación del sujeto femenino frente al orden simbólico patriarcal, que, en tanto rebeldes, las tiene por amenaza.

Que un personaje femenino en la escritura recomponga como duda el lugar de la mujer como madre y lo que implica y significa ser o no ser madre no es, en sí mismo nuevo, como puede verificarse en las lecturas que Irigaray y Marianne Hirsch realizan en la historia literaria, y que las hace, inevitablemente, comenzar su análisis en los mitos griegos. En este sentido, ni las novelas de Leduc ni la novela de Franck se posicionan como obras que abren una nueva temática, sino que continúan con una larga práctica que enlaza las estructuras sociales y el orden simbólico literario en torno a la cuestión de los límites, características y posibilidades del significante mujer-madre. Así también, particularmente estos casos, el de Leduc y Franck, encuentran eco en sus contextos de origen y publicación: en la primera, a la par del surgimiento de un feminismo de segunda ola, y en la segunda junto a los conflictos y debates que surgieron en los últimos años en Alemania en torno al rol de madres de las mujeres, que remitió a viejos debates feministas de largo alcance en ese país.

En las intensas imágenes poéticas de Leduc y en las detalladas y frondosas narraciones de Franck el resultado parece ser, en gran parte, bastante determinante: la trama-madre hija es el motor de la escritura por experiencias personales, en los dos casos tiene un origen basado en el trauma y conflicto que, como apuntaba Irigaray, gesta un silencio, una falta de entendimiento entre madre e hijas, que la narrativa permite materializar en la palabra literaria. La palabra escrita en la trama madre-hija es la forma de materializar un vínculo desaparecido, borrado; la forma de las palabras recupera su silueta original, lo retuerce, desafía, exige su reconocimiento con conflictos y lo restaura en un modo que nunca es su imagen espejo.

Bajo este paradigma encontramos muestras de literatura feminista en Leduc y en Franck, en dos idiomas y tradiciones literarias disímiles, que concretan, como sugiere Irigaray en sus escritos filosóficos-feministas, un espacio entre mujeres que resiste el orden androcéntrico impuesto y que construyen en formas de la trama madre-hija, una posibilidad de orden simbólico de la madre y de la relación entre mujer y maternidad que, si algo abandona, es el binomio.

\section{Referencias bibliográficas}

BenKov, E. J. (1994): «Violette Leduc», en S. MALINOWSKI, ed., Gay and Lesbian Literature. Detroit, St. James Press, pp. 220-223.

BreE, G. (1973): Women Writers in France. New Brunswick, Rutgers University Press.

BIENDARRA, A. S. (2004): «Gen(d)eration Next Prose by Julia Franck and Judith Hermann», ST\&TCL 28 (Invierno 2004), pp. 211-239.

De Courtivron, I. (1985): Violette Leduc. Boston, Twayne. 
(1994): «Violette Leduc (1907-1972)», en E. MARTIN SARTORI y D. Wynne Zimmerman. French Women Writers. New York, Greenwood.

De Peretti, C. (1989): «Entrevista con Jacques Derrida», Derrida en castellano, en http://www.jacquesderrida.com.ar/textos/derrida_entrevista.html (última consulta, 6-5-2015).

DonAth, O. (2014): «Regretting Motherhood», Signs: Journal of Women in Culture and Society, 40/2.

FELl, A. S. (2003): Liberty, Equality, Maternity in Beauvoir, Leduc and Ernaux. Oxford, Legenda/EHRC.

Flanner, J. (1971): Paris Journal: Volume 2, 1965-1971. W. Shawn, ed., New York, Atheneum.

FORCINITO, A. (2004): Memorias y nomadías: géneros y cuerpos en los márgenes del posfeminismo. Santiago, Cuarto Propio.

FRANCK, J. (2007): Die Mittagsfrau. Frankfurt, Fischer.

_ (2008): «The Wonder (of) Woman», Women in German Yearbook, 24, pp. 229-240.

_ (2009): La mujer del mediodía. Trad. Belén Santana López. Barcelona, Tusquets.

FrANTZ, A. (2009): «The repentance of a bastard. A study of Violette Leduc», Sens Public, en http://www.sens-public.org/IMG/pdf/SensPublic_AFrantz-VioletteLeduc_eng_pdf (última consulta, 20-4-2015)

GEU, S., y FRANCK, J. (2007): «Schreiben zum Überleben. Interview», ZEIT online, en http://www.zeit.de/online/2007/40/interview-julia-franck (última consulta, 10-2-2015).

HiLl, A. M. (2014): «The Childless Woman as Failure; or, the "Spinster Aunt" as Provocation for the Future», Women in German Yearbook, 30, pp. 164-174.

HIRsCH, M. (1989): The Mother/Daughter Plot: Narrative, Psychoanalysis, Feminism. BloomingtonIndianapolis, Indiana University Press.

Hughes, A. (1994): Violette Leduc: Mothers, Lovers, and Language. London, MHRA.

IRIGARAY, L. (1981): Les Corps-à-corps avec la mere. Montreal, Pleine Lune.

- (1985): El cuerpo a cuerpo con la madre. El otro género de la naturaleza. Otro modo de sentir. Trad. Mireia Bofill y Anna Carvallo. Barcelona, LaSal. (1992): Yo, tú, nosotras. Trad. Pepa Linares. Madrid, Cátedra.

_ (1998): Ser dos. Trad. Patricia Wilson. Buenos Aires, Paidós. (2007): Espéculo de la otra mujer. Trad. Raúl Sánchez Cedillo. Madrid, Akal.

KRISTEVA, J. (1995): Historias de amor. México, Siglo XXI.

LEDUC, V. (1946): L'Asphyxie. Paris, Gallimard.

— (1955): Ravages. Paris: Gallimard.

_ (2000): Thérèse et Isabelle. Paris, Gallimard.

Locey, E. (2002): The Pleasures of the Text: Violette Leduc and Reader Seduction. Maryland, Rowman \& Littlefield

Marks, E. (1979): «Lesbian Intertextuality», en G. Stambolian y E. Marks, eds., Homosexualities and French Literature. Ithaca, Cornell University Press, pp. 353-377. 
Merley, H. (2009): Maternal Drag: Identity, Motherhood and Performativity in the Works of Julia Franck. Amherst, University of Massachusetts Amherst.

Moreno, M. (2005): Vida de vivos: conversaciones incidentales y retratos sin retocar. Buenos Aires, Sudamericana.

Rodríguez Magda, R. M. (1994): «El feminism francés de la diferencia», en C. AMOrós, ed., Historia de la teoría feminista. Madrid, Instituto de Investigaciones Feministas-UCM.

WhiTe, E. (1993): Genet: A Biography. New York, Knopf.

ZERILLI, L. M. G. (1996): «Un proceso sin sujeto: Simone de Beauvoir y Julia Kristeva sobre la maternidad», en C. ALDA, ed., Figuras de madre. Valencia, Universitat de València, pp. 155188. 